\title{
NÃO-AGIR PARA AGIR, UM PARADOXO E UMA UNIDADE DINÂMICA ${ }^{1}$
}

Mariane Magno²

Resumo

O texto propõe a aproximação possível entre diferentes vertentes de pensamento que integram tanto o corpomente como unidade, quanto a atualização da ação. Tais investigações são propostas a partir de certa compreensão psicofísica ${ }^{3}$ como experiência auto-poética. Tecnicamente, em corpo-ator, como reorganizações (criações) sensíveis e eficazes que possibilitam a concretização da imaginação (passagem do efeito e do sutil) no eixo do tempo-espaço poético.

Palavras-chave: corpo-ator, concentração, presença cênica.

Abstract

The text proposes a possible approximation between different strands of thoughts that integrate both the body-mind as unity as well as the accomplishment of the action. Such investigations are proposals that depart from a certain psychophysical understanding as a self-poetic experience. That is to say, technically, in body-actor, as sensitive and efficient reorganizations

(creations) that enable the implementation of the imagination (the passage of the effect and the subtle) on the axis of the poetic time-space.

Keywords: body-actor, concentration, stage presence. 


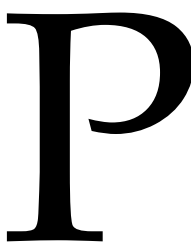
ara propor o princípio da mutabilidade não-agir para agir como unidade dinâmica em corpo-ator ${ }^{4}$ é preciso iniciar pela sua gênese no pensame'nto filosófico chinês e taoísta. Faremos isso a partir do conceito vivo que François Jullien ${ }^{5}$ (1998) apresenta como não-ação, o qual se distingue daquilo que, ocidentalmente, identificamos apenas como inação: (...) tendeu-se a interpretar o seu não-agir como simples avesso de nosso agir heroico, invertendo esse, portanto, no sentido da renúncia da passividade ${ }^{6}$ (JULLIEN, 1998, p. 108).

Localizar o agir ${ }^{7}$ no contexto taoísta implica em observá-lo simetricamente sob um duplo pressuposto: figurar a conduta humana como um fazer específico (ergon, práxis; e, novamente, o modelo técnico da produção serve de referência) e conceber a ação como uma entidade própria, insolável, e capaz de servir de unidade e de base de conduta (JULLIEN, 1998, p. 63).

1 Este artigo está enraizado na pesquisa de doutorado desenvolvida na Pós-Graduação do Instituto de Artes da Unicamp, a qual pesquisa teve o seu foco centrado na imaginação do ator em processo criativo.

2 Atriz, diretora, pesquisadora. Mestre e doutora em Artes, IA-UNICAMP. Email: marianemagno@hotmail.com.

3 Fundamentados a partir dos princípios do método stanislavskiano das ações-físicas e seu desenvolvimento nas práticas teatrais contemporâneas. Utilizamos como referência certos desenvolvimentos e desdobramentos em Barba e Savarese (1995), Dagostini (2007), Grotowski (2007) e Ruffini (1995)

4 Expressão utilizada por Ribas, M. M. (2009), para distinguir (pedagogicamente) certo tempo-estado, o do 'ser ator' em estado de trabalho.

5 François Jullien é professor da Universidade Paris VIII, filósofo, sinólogo especializado em China e Grécia antiga.

6 "(...) (O ocidente "ativo" sonhando ter no oriente seu repouso...). Ora, bem longe de pregar um desinteresse pelos assuntos humanos, de propor um afastamento do mundo, o não-agir do Laozi ensina como se conduzir nele para ser bemsucedido." (JULLIEN, 1998, p. 108)

70 que se pode pretender, na verdade, suficientemente unitário e separado, no seio do comportamento - que seja autoconsciente e suficientemente independente de todo contexto, e acima de tudo do antes e do depois - para que se possa destacá-lo com tal na trama de nossa existência? Existe uma realidade própria, que tenhamos condições de assinalar e identificar, e que podemos chamar ação? Os pensadores chineses poderiam duvidar disso, eles que consideram a conduta humana como qualquer outro curso, em termos de processo, regulado e contínuo (JULLIEN, 1998, p. 63).
Introduzir este breve estudo sobre o agir, sob estes dois pressupostos taoístas, todavia, nos afasta, de certo modo, do mito ocidental da ação ${ }^{8}$ e aponta o sentido do pensamento taoísta sobre o culto do agir, que não evidencia nem o heroico e nem o trágico. Esta percepção produziu um pensamento que não escolheu interpretar o real em termos de ação.

Contextualizamos o não-agir, por conseguinte, como parte interada na unidade não-agir para agir, sob a luz da filosofia chinesa e taoísta, como uma compreensão em vida que gera certa visão de mundo que, por sua vez, engloba vínculos em experiência entre as práticas corporais, a fluência da energia vital, a medicina, a filosofia, a arte, a mitologia, a atitude política e as leis da natureza. Vínculos estes que, na condição humana, integram à percepção e à ação o melhor aproveitamento da fluência da energia vital, em corpo, a qual estabelece relações dinâmicasentremicrocosmoemacrocosmo; ou seja, o Tao Humano e o Tao do Mundo entrelaçados ininterruptamente. Esta adequação dinâmica àquilo que já é potencial aponta o sentido da eficácia.

A dinâmica do pensamento taoísta, deste modo, propõe um sentido em vida muito distante da lógica racional e científica ocidental que, por sua vez, se organiza e evolui pela linearidade do pensamento objetivo e sucessivo. Esta linearidade, a do pensamento científico ocidental, é incompatível com o conhecimento vivo no Tao Te King, um dos clássicos que fundamenta o taoísmo. A sabedoria milenar viva nesta literatura se faz aberta e,

8 Tanto mais que a ação é, de fato, o objeto próprio ao mythos, concebido exatamente como relato de ação, pelo qual teve início a civilização europeia. Repassemos, pois, essas imagens, elas que estão entre as primeiras da história de nossa razão. Deus, seja o da tradição judaico-cristã ou o do Timeu, faz o mundo existir por meio de um ato criador; e é próprio do herói também imprimir sua ação sobre o mundo, enfrentando-o: com a epopeia, a literatura começou pelo relato de atos memoriáveis, enaltecidos a título de façanhas, depois a tragédia os encenou (sendo próprio do teatro, lembra Aristóteles que ainda não possuía termo para o que chamamos personagem, representar os homens "enquanto age", prattontes). Constatação sumariamente banal, mas que o é menos vista da China (JULLIEN, 1998, p.68). 
de certo modo, misteriosa e escorregadia, pelo seu caráter dinâmico, aforístico e enigmático. Falar sobre esta vertente de conhecimento milenar, portanto, significa apenas a aproximação possível para que se preserve 'certo espaço aberto' porque o Tao não se esgota, e, o 'Tao verdadeiro', atinge o indizível.

Esta obra clássica, o Tao Te King, pode ser interpretada (ocidentalmente) como paradoxal, maséexatamentena(s) lacuna(s) exegética(s) (sob a perspectiva ocidental) que é possível identificar o conhecimento latente, oculto e/ou contraditório; ou seja, a lacuna é o espaço indispensável para que se possa preservar o movimento mutante que é o fundamento do taoísmo. É nela, na 'lacuna', que (segundo a filosofia taoísta) é possível gerar a potência do encontro que nutre a mutabilidade entre as forças que se atraem, se fundem, se alimentam e se transformamumana outra.Porconseguinte, sob a ordem da filosofia taoísta, é no espaço defusões dinâmicas (entre o não-agir e o agir) que se localiza o eixo vivo que atua como princípio da mutabilidade em constante atualização. Assim, a percepção (não-agir) e a integração (agir) do imanente (porvir, potencial) como unidade possibilitam a preservação da dinâmica da mutabilidade (virtude), isto é, são os fundamentos vivos desta unidade igualmente viva que têm como eixo o 'vazio'.

Aqui se trata do vazio funcional de Laozi ${ }^{9}$ que se exerce por relação com o pleno e graças ao qual o pleno pode cumprir seu pleno efeito $^{10}$ (JULLIEN, 1998, p. 135) que se diferencia do vazio da inexistência, que se inscreve numa perspectiva metafísica do ser e do não-ser: é o vazio do budismo (sunya, em sânscrito; cf. king, em chinês) (JULLIEN, 1998, p.135).

9 Laozi, Lao Tzu, Lao Tsé, Lao Tzi, Lao Tseu ou Lao Tze (1324 a.1408 a.C.) - filósofo e alquimista chinês a quem é atribuída a escrita do Tao Te King

10 Direcionamos o efeito filosófico taoísta às aproximações possíveis em corpo-ator, ou seja, em realidade criativa e poética. Trata-se de certa qualidade de atuação encontrada em Stanislavski pela qualidade da ação consequente dos músculos livres (nota $\mathrm{n}^{\circ} 12$ ); em Lowen, pela liberdade interior (nota $\mathrm{n}^{0} 10$ ) e em Grotowski pela passagem do pesado para o sutil(p. 11).
Deste modo, para compreender o duplo pressuposto como unidade mutante, não-agir para agir, é preciso evidenciar a existência de outro elemento-chave, o processamento constante (virtude) que atua como a força viva indispensável à mutabilidade.

Por conseguinte, o vazio, como eixo, permite a passagem do efeito, já que, para a filosofia taoísta, o efeito não pode ser obtido diretamente, ou seja, ele, o efeito, não deve ser buscado mas colhido. Tal afirmação nos leva à não-ação como estratégia, pois a intenção mata o efeito, seca-o, esgota-o (JULLIEN, 1998, p. 148). Direcionamos, portanto, o foco do pensamento no movimento vivo, ou seja, no processo como unidade que é o montante, a título de condição, é o único capaz de conduzir ao pleno efeito (a título de efeito) (JULLIEN, 1998, p. 149). Não-agir em processo e em corpo-ator pode ser o efeito gerado como qualidade da atuação que se faz pela atenção, calma e autodomínio cênico, e que, juntos, não antecipam mentalmente a ação, e, por isso, podem gerar uma compreensão a mais que advém da experiência a seu tempo (potencialização do agir), aquela que só acontece no momento presente. Esta compreensão (não-agir), portanto, não pode ser prevista e tampouco imposta porque se trata da escuta sensível, no ato, que antecede, alimenta e se transforma em agir.

Bachelard (1998) em sua expressão noturna fala brilhantemente sobre a via negativa como possibilidade e como caminho à ampliação e superação dos limites da consciência, para ele o não-saber não é uma ignorância, mas um ato difícil de superação do conhecimento. É a esse preço que uma obra é a cada instante essa espécie de começo puro que faz de sua criação um exercício de liberdade (BACHELARD, 1998, p.16).

Deste modo, a partir do princípio mutante não-agir para agir como processo e como unidade é possível arriscar uma aproximação a mais entre o pleno efeito taoísta e a sinceridade artística na busca 
da plenitude, em Grotowski (2007). Essa aproximação com a sinceridade só acontece sem forçar e sem simular, e, conforme dito parágrafos acima, por Jullien, a intenção mata o efeito, seca-o, esgota-o; e, por Bachelard a via negativa é um ato difícil de superação do conhecimento. Portanto, na condição humana, na linguagem teatral e em corpo-ator ${ }^{11}$ a via negativa pode ser um caminho, um lugar onde não somos divididos. (...) Se cumprimos o ato com todo nosso ser, como nos instantes do verdadeiro amor chegará o momento em que será impossível decidir se agimos conscientemente, ou inconscientemente. Em que é difícil dizer se somos nós a fazer algo ou se isso nos acontece (GROTOWSKI, 2007, p. 211).

A não-ação, portanto, pode ser interpretada filosoficamente como a ação que não constrange ou a ação que não força. Mas, temos de esclarecer um pouco mais a expressão 'ação que não constrange', ou 'ação autêntica', como a limpeza (transformação) daquilo que é excessivo no agir e que não passa pela retidão moral ou por julgamentos, e que não

nos levam a cindir o mundo em dois, a opô-lo a ele mesmo (o bem e o mal) e, finalmente, a mutilá-lo. Porquanto, ao suprimirmos um para valorizar o outro, anulamos sua interdependência, perdemos de vista sua coerência. Devese, portanto, entender virtude nesse outro sentido que, não mais remete ao dever ser, é da ordem da efetividade: no sentido de uma qualidade que torna próprio para um certo efeito, ou seja, que possui capacidade de produzi-lo (JULLIEN, 1998, p. 117).

11 Neste momento direcionamos o estado de atenção e de concentração em trabalho criativo a percepções mais profundas e, assim, nos aproximamos do self corporal. Esta dimensão, self, é possível de ser alcançada pela liberdade interior (que tem aspectos biológicos) indispensável para tal vivência. A liberdade interior manifesta-se na graciosidade do corpo, em sua suavidade e vitalidade. Corresponde a estar livre de culpa, vergonha e constrangimento. É uma qualidade de ser que todos os animais selvagens possuem, mas que está ausente na maioria dos seres civilizados. É a expressão física da inocência, de um modo de agir espontâneo, sem artifícios e verdadeiro para o self. (LOWEN, 1997, p.23) Cabe, ainda, evidenciar que a liberdade interior é condição para atingir certa qualidade psicotécnica e psicofísica em corpo-ator (liberdade), independente de seus conteúdos dramatúrgicos.
No universo literário, por princípio, na fenomenologia líquida bachelardiana, encontramos correspondência daquilo que é apresentado como a via negativa da ação ou, ainda, como um duplo pressuposto.

Portanto, é preciso que o saber seja acompanhado de um igual esquecimento do saber. (...) Em poesia, o não-saber é uma condição prévia; se há o ofício no poeta, é na tarefa subalterna de associar imagens. Mas a vida em uma imagem está em toda sua fulgurância, no fato de que a imagem é uma superação de todos os dados da sensibilidade (BACHELARD, 1998, p. 16).

Assim, propomos a unidade, não estar dividido em corpo-ator, como um senso de autodomínio e de curiosidade que se desenvolve pela fusão entre forma (movimento, aspecto aparente) e não-forma (motilidade, ${ }^{12}$ vitalidade e inconsciente). O desenvolvimento deste estado vivo, em corpo-ator, pode ampliar o território consciente sobre si mesmo e sobre sua imaginação que, por sua vez, pode potencializar a motilidade e a autoexpressividade da presença cênica; ou seja, a imaginação é viva em corpo, ela tem aspectos biológicos e energéticos, sejam eles conscientes ou não. Identificamos nestas compreensões psicotécnicas a dilatação corporal apresentada por Barba e Savarese (1995), a qual, segundo Ruffini (apud BARBA e SAVARESE, 1995, p.64) está vinculada à presença que nesta definição está quase livre de qualquer conotação metafórica. Ela é literal.

12 Aproximaremos a motilidade da psicologia formativa dos processos psicofísicos e psicotécnicos: presença, dilatação e irradiação. Para Keleman, o movimento descreve como as criaturas se deslocam de um lugar para outro. Da perspectiva do processo somático, o movimento é mecânico. Articulações e ossos flexionam, dobram, giram, deslizam; músculos levantam, empurram, puxam, apertam, contraem, alongam. A motilidade, por outro lado, brota dos processos metabólicos da existência. A excitabilidade da célula, sua expansão e polarização são exemplos de motilidade, assim como os acessos emocionais, tais como, raiva ou medo. (KELEMAN,1992, p. 32) Esta motilidade inerente ao corpo vivo, que é a base de sua atividade espontânea, resulta de um estado de excitação interna que irrompe continuamente na superfície em movimento. (LOWEN,1985, p. 19) 
A reorganização psicofísica deste estado de trabalho, presente, vivo e dilatado, ${ }^{13}$ implica no desacelerar da mente e no direcionamento volitivo da atenção (sincronia corpo-mente), que conduz a certa compreensão psicotécnica em concentração, ou seja, à percepção sensível daquilo que se faz (consciente e volitivo) com a integração poética daquilo que emerge (involuntário, inconsciente), em dinâmica constante.

A Concentração é o elemento primeiro do método das ações-físicas que envolve a observação, a percepção, a imaginação, a memória e a vontade (DAGOSTINI, 2007, p. 62). Este elemento técnico se faz pela integração dinâmica de diversas faculdades que se alimentam e se provocam entre si, as quais, em função mutante, permitem a passagem do efeito como a qualidade da ação - a interação viva que se presentifica como acontecimento. A concentração é o primeiro alicerce, é o germe da criação. (...) Este material sensitivo-emocional é valioso para dar forma à 'vida do espírito humano do papel' objetivo principal da arte teatral (DAGOSTINI, 2007, p. 63).

É preciso, entretanto, tomar certo cuidado com as palavras, pois, não-agir para agir em corpo-ator não é proposto como abandono de si (desatenção), mas, sim, como certo desenvolvimento sensível da atenção em intensa concentração, pela qual, se estabelece uma condição, um estado, que leva a uma ação interior ativa (...). K. Stanislávski destaca o caráter ativo da atenção cênica, que se revela através dos círculos de atenção (DAGOSTINI, 2007, p. 63).

Tal estado de trabalho, deste modo, está vinculado a outro elemento do método stanislavskiano liberdade muscular que desvia o trabalho do ator de certos excessos, entre eles, o de tensão, o de força (a inútil) e o de vontade (resgatamos

13 Ruffini (apud BARBA e SAVARESE, 1995) para falar da equivalência viva como presença entre a dilatação física e a mental (logo, psicofísica) recorre aos ensinamentos de K. Stanislávski: O objetivo direto e declarado do trabalho do ator, de acordo com Stanislávski, é a recriação da organicidade. Por meio do sistema o ator aprende a estar presente organicamente no palco, antes e separadamente dos papéis que ele terá de representar (RUFFINI apud BARBA e SAVARESE, 1995, p. 64) nesse elemento, vontade, a via negativa de Jullien e de Bachelard expostos na página 03). Evidenciamos que dissemos excessos, já que, certa força, certa tensão e certa vontade são elementos, em corpoator, que compõem a atuação cênica. Deste modo, o conceito satnislavkiano, liberdade muscular, é compreendido e proposto como consequência (efeito) da melhor fluência da energia vital, como liberdade interior e, ainda, como compreensões mais sutis aproveitadas, de forma poética, em corpo-ator e em treinamento dinâmico.

Segundo Dagostini (2007) Stanislávski ${ }^{14}$ apresenta a importância da atenção, da firmeza, da flexibilidade, da concentração e da destreza como psicotécnica, ou seja, "considera que a tensão e o esforço físico em cena são causados pela violação das leis da natureza" (DAGOSTINI, 2007, p.85). Ele propõe deste modo o treinamento psicofísico para o desenvolvimento de um corpo relaxado e atento, pois apenas a natureza em totalmedida pode dirigir nossos músculos, ou seja, relaxá-losetensioná-losadequadamente. Assim, para expor a qualidade 'natural ${ }^{15}$ ' em corpo-ator expressa como inteligência em ação eficaz que se vincula à adequação do tônus muscular, evocamos um exemplo clássico stanislavskiano - pela voz do grande mestre russo: Quem me ensina melhor do que meu gato? (STANISLÁVSKI, 1954 apud DAGOSTINI, 2007, p. 87).

14 K. Stanislávski, além de ter determinado um treino físico diário, adotou, nessa primeira etapa prática do estudo do elemento liberdade muscular, um programa pedagógico que consistia de exercícios de sensibilização, percepção, equilíbrio, força, resistência, agilidade, destreza e consciência do fluxo da energia interna do movimento. Esse processo era guiado de tal forma que contemplava o desenvolvimento e o aperfeiçoamento da vontade, da imaginação, da atenção, da memória, de habilidades cênicas especiais, e, sobretudo visando à realização concreta de uma ação orgânica, plasticamente expressiva, dirigida a um fim (DAGOSTINI, 2007, p.85). (...) É neste elemento do "sistema", liberdade muscular, que K. Stanislávski lança as bases dos princípios teóricos e práticos da cultura corporal que vão reger a pedagogia da área: Fundamentos do movimento cênico, da escola soviético/ russa. Todas as práticas corporais estão subordinadas a esta área (...) (DAGOSTINI, 2007, p. 88).

15 Natural é utilizado como a 'segunda natureza' proposta igualmente por Stanislávski como qualidade psicotécnica (organicidade) integrada como domínio cuja conquista pode ser elaborada pelos treinamentos sistematizados e utilizados por certo tempo. 
Os movimentos do gato, deste modo, passam a ser objeto dos estudos corporais stanislavskianos, tanto da fluência de energia quanto da eficácia de seus movimentos e de suas ações:

(...) tal harmonia dos movimentos e tal desenvolvimento corporal, como os dos animais, sãoinacessíveis para o ser homem. Não existe técnica que consiga tamanha perfeição no que tange ao domínio dos músculos. Somente uma natureza inconscientemente apta pode alcançar tal virtuosismo, facilidade, precisão, desenvoltura dos movimentos, poses, e tal plasticidade (STANISLÁVSKI,1954 apud DAGOSTINI, 2007, p. 87).

As qualidades da atenção, da firmeza, da liberdade muscular e da precisão observadas nos movimentos do gato, se aproximam do imaginário animalizante chinês pelo 'passo do tigre'. ${ }^{16}$ Ambos, a partir de certa concentração, propõem o desenvolvimento da leveza, do autodomínio do movimento (graciosidade e vitalidade), da atenção, da flexibilidade, da fluência de energia vital, e, por fim, a transformação natural dos movimentos. Qualidades técnicas vinculadas à liberdade muscular, a qual, por sua vez, pode ser treinada (ainda que nos limites humanos) a partir da fluidez

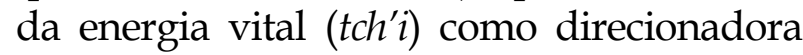
e formadora da forma, enquanto se forma.

Indo adiante nas possibilidades de equivalência entre o princípio não-agir para agir e os ensinamentos de Grotowski,

16 'Passo do tigre’ ou 'pisar na lama' são expressões utilizadas para definir certo modo e qualidade (expandir e recolher) de andar no treino do 'pakuá', uma sequência sistematizada de treino marcial chinês que se faz em círculo e tem seus movimentosfundamentados nos oitotrigramas do IChin (Qian, Zhen, Kan, Gen e Kun, Xun, Li e Dui) e suas mutações. Neste modo de andar é possível exercitar e trabalhar qualidades de movimento como relaxamento, atenção, firmeza, concentração, relação, fluência (expansão e recolhimento), potencializaçao da ação e, ainda, transformações do movimento com reorganizações musculares mais adequadas através das palmas (sequências de ações que configuram a sequência da forma 'pakuá'), propostas como arranjos do mundo interior. São elas, as palmas: leão, quimera, serpente, águia, dragão, urso, fênix e macaco; e que atuam como a representação do mundo material - respectivamente: céu, terra, água, fogo, trovão, montanha, vento e lago. 0 'passo do tigre' é utilizado no caminhar entre troca de palmas. evocamos sua própria voz e propomos, deste modo, uma possibilidade para se pensar a via negativa grotowskiniana sob a luz deste princípio dinâmico e taoísta, o agir sem agir: o próprio processo, mesmo que até um certo ponto dependa da concentração, । da confiança, do desvelamento e quase da aniquilação no ofício, não é voluntário. O estado mental necessário é uma disponibilidade passiva para realizar um papel ativo, um estado no qual não se "quer fazer aquilo" mas antes "renuncia-se a não fazê-lo (GROTOWSKI, 2007, p. 106).

Retornando às diferenças entre as 'perspectivas' ocidental e taoísta, ao observar, por exemplo, a noção do tempo é possível perceber que os chineses não se relacionam sob o aspecto da duração pela sucessão e uniformidade como no ocidente e, sim, pelo conjunto de eras, estações ou épocas: os chineses conceberam lugares e ocasiões, e não espaço ou tempo em si (JULLIEN, 2004, p. 39). A adaptação do Homem à estação é uma condição que atualiza a atitude adequada (eficaz) a qual intera os ciclos da Natureza e não antecipa e não retarda as ações e, sim, age junto. É com esta compreensão 'em tempo' que eles, os chineses taoístas, 'caminham pelo tempo' uma estação após a outra, construindo o seu gênero de vida, fundamentado na lei da eficácia.

Sob a compreensão do pensamento ocidental podemos nos direcionar a este conceito de tempo, aproximadamente, como ocasião; para os chineses taoístas a experiência tempo é como um momento sazonal, ou, conforme Jullien (2004), captar a imanência:

O fato de a ocasião se oferecer como um momento privilegiado para agir, até mesmo dela determinar sozinha o sucesso, como gostam de repetir os antigos chineses, deve-se ao seu caráter conjuntural, permitindo a particularidade qualitativa da adaptação; ao mesmo tempo, deve-se ao seu caráter evolutivo, que promete 
um desenvolvimento que virá do efeito implicado- tal como a estação (...) A ocasião corresponde assim à situação (grifo nosso) (...) Trata-se aqui, não do 'tempo', mas do tempo oportuno (JULLIEN, 2004, p. 47). ${ }^{17}$

Por esta perspectiva 'invertida', a objetividade prévia, como é identificada ocidentalmente, é considerada, sob a filosofia taoísta, apenas uma parte da possível unidade, e, por isso, sozinha, a objetividade prévia (como imposição) por ser fechada ${ }^{18}$ não levaria à dinâmica da mutabilidade adiante. $\mathrm{O}$ que existe é a percepção do tempo como ocasião, cujo processamento acontece pela nãoação, isto é, a receptividade do tempo como uma ação indireta que se desenvolve pela percepção e maturação daquilo que é favorável no momento, ou seja, a potencialização da ação, já que, a forma desvinculada da sua nascente não-forma é considerada ação desconexa, logo ineficaz.

Por conseguinte, filosoficamente, nãoagir é um espaço vivo, de absorção e de compreensões múltiplas, é o momentoespaço do qual se forma e emerge a manifestação de uma força ou a operação de um agente. $E$, ao direcionar este conceito filosófico ao estado poético como imagem corpo-ator, nos aproximamos da topofilia bachelardiana, ou seja, as imagens do espaço feliz:

Nessa perspectiva, nossasinvestigações
mereceriam o nome de topofilia.
Visam determinar o valor humano
dos espaços de posse, dos espaços
defendidos contra forças adversas, dos
espaços amados. Por razões não raro
muito diversas e com as diferenças
que as nuanças poéticas comportam,
são os espaços louvados. Ao seu valor
de proteção, que pode ser positivo,
ligam-se também valores imaginados,
e que logo se tornam dominantes
(BACHELARD, 1993, p.18).

17 Ao leitor interessado neste "tempo" ver: JULLIEN, F. (2004),

18 Retomamos a citação da página 03 "a intenção mata o efeito, seca-o, esgotá-o".
Mas, cabe ainda chamar a atenção igualmente para o agir, pois sem a forma e sem a estrutura (agir) a não-forma (potencialização) se dissolve. E, ainda, sem a dinâmica entre forma e não-forma, não há a mutabilidade, não há a experiência e nem o sentido, ou seja, o processo é o aproveitamento da dinâmica constante - a unidade em ação.

Esta inversão da percepção - citada na página anterior - que apresenta a ocasião como determinante, 'dela determinar sozinha', não é uma atitude desconexa e apenas passiva, e, tampouco, fantasiosa. É, sim, um estado de recepção que, sob a percepção ocidental, acaba por propor inversões, a do sentido da atenção e da direção do pensamento. Mas, em corpo-ator e sob a luz da imaginação, de fato, ela atua como certa conexão que pode levar a uma escuta sensível, como um silêncio vivo, que possibilita compreensão e adequação ao oportuno no momento, ou seja, um espaço ${ }^{19}$ para se perceber, se pensar e atualizar a dinâmica da ação e a da consciência. ${ }^{20}$ (...) A consciência, por si só, é um ato, um ato humano. É um ato vivo, um ato pleno. Mesmo que a ação que se segue, que deveria seguir-se, que deveria ter-se seguido, permaneça em suspenso, o ato consciencial tem sua plena positividade (...) (BACHELARD, 2006, p. 05).

Podemos aproximá-lo, o não-agir, à luz do arquétipo feminino o qual se intera com seu complementar masculino e, da união viva entre ambos, é possível preservar o movimento capaz de gerar mais vida. Assim, sob a luz taoísta, agir sem agir não é um paradoxo, é, sim, um conuinctio vivo em dinâmica mutante.

Para aproximarmos este duplo pressuposto taoístas de processos criativos

19 É que o espaço percebido pela imaginação não pode ser o espaço indiferente entregue à mensuração e à reflexão geômetra. É um espaço vivido. Evivido não em sua positividade, mas com todas as parcialidades da imaginação. Em especial, quase sempre ele atrai. Concentra o ser no interior dos limites que protegem (BACHELARD, 1993, p. 19).

20 Consciência, neste contexto, se direciona a mudança de eixo apresentada por Bachelard, ou seja, verticalidade do instante poético. 
cênicos e poéticos, ou seja, em corpo-ator, como unidade não-agir para agir, é preciso integrar um elemento e um vínculo a mais. Estes caminhos nos levam novamente a Jullien (1998), quando expõe a estrutura da 'ocasião' que apresenta de um lado 'o acaso' e do outro 'a arte'. Para ele:

(...) o acaso de um lado e a arte, do outro: entre tychê e techne, interpõem-se um terceiro termo para pensar a ação - a ocasião (kairos). (...), entre aquilo que, de um lado, depende da fortuna (ou da "divindade") e, do outro, aquilo que é "nosso" (a técnica), a ocasião operaria a junção de onde provém a eficácia: ela é o momento favorável que é oferecido pelo acaso e que a arte permite explorar; graças a ela, nossa ação é capaz de inserir-se no curso das coisas, ela já não faz um arrombamento, mas consegue enxertar-se nele, aproveitando-se de sua causalidade e sendo auxiliada por ele. Graças a ela, o plano concertado consegue encarnar-se, esse momento oportuno nos dá poder, assegura nosso domínio (JULLIEN, 1998, p. 81).

Deste modo, a ocasião (melhor seria dizer, a percepção e o aproveitamento da ocasião), é aproximada do tempo grego kairótico (forma qualitativa de tempo, momento certo ou oportuno) e do conceito de arte proposto por Stanislávski (apud DAGOSTINI, 2007) à linguagem teatral, o qual conceito reside na efemeridade e na transformação, possíveis apenas na comunhão do momento presente. Agindo lógica e coerentemente, você força a sua natureza orgânica a trabalhar e, dessa forma, o subconsciente. Em nossa arte isso é fundamental, através do consciente alcançar o subconsciente (STANISLÁVSKI apud VINOGRADSKAIA 2000, in DAGOSTINI, 2007, p. 127).

Ao direcionar o princípio da mutabilidade à materialidade criativa em corpo-ator (imaginação) é possível ampliar, um pouco mais, a leitura de Grotowski (2007), ao dizer: consideramos que a composição artificial não só limite o que é espiritual que na realidade conduza a ele. A tensão tropística entre o processo interior e forma reforça ambos. A forma é como uma armadilha munida de isca à qual o processo espiritual responde espontanemante e contra a qual luta (GROTOWSKI, 2007, p. 106).

Corporalmente,melhordizerpsicofísica e psicotécnicamente, estes princípios vinculam a compreensão em corpo-ator como experiência integrada que cumpre sua eficácia, como efeito, na vivência poética do ser. Para Jung (1991) a criação poética é um acontecimento suprapessoal e, este mesmo acontecimento, sob a fenomenologia Bachelardiana, altera a horizontalidade no eixo vertical, o instante poético. A compreensão sobre o ato poético em Jung e em Bachelard, nas nossas aproximações investigativas, nos 'aterram', em corpoator, na verticalidade grotowskiniana, que é a passagem energética para um nível mais sutil. Tal passagem, por sua vez engloba a questão do descer trazendo de novo essa coisa sutil dentro da realidade mais comum, ligada à densidade do corpo (GROTOWSKI, 2007, p. 235).

O estado poético em corpo-ator, por conseguinte, se acontece, é sob a ação da imaginação; e, (...) graças ao imaginário, a imaginação é essencialmente aberta, evasiva. É ela no psiquismo humano, a própria experiência da abertura, a própria experiência da novidade (...). Como proclama Blake: A imaginação não é um estado, é a própria experiência humana (BACHELARD, 2001, p. 01).

Assim, direcionando a imaginação, a motilidade da presença, a verticalidade e o sutil ao universo investigativo em corpo-ator,

não se trata de renunciar a uma parte de nossa natureza, tudo deve ter o seu lugar natural: o corpo, o coração, a cabeça, algo que está "sob os nossos pés" e algo que está "sobre a cabeça". Tudo com uma linha vertical, e esta verticalidade deve ser esticada entre a organicidade e the awareness. Awareness, quer dizer a consciência que não é ligada à linguagem (à maquina para pensar), mas a presença (GROTOWSKI, 2007, p. 235). 
Por conseguinte, o 'revivescer' de tais qualidades e conceitos psicotécnicos em corpo-ator implica no trabalho insistente e detalhado, por certo tempo, até que os procedimentos e princípios propostos aos treinamentos corporais sejam suficientemente integrados, e, por essa integração dos conceitos técnicos evocamos outro princípio do método das ações-fisicas, a adaptação. Assim, a adaptação stanislavskiana inclui o autodomínio técnico, integrado em corpo-ator, suficiente, o qual engloba a dinâmica mutante que o atualiza entre o não-agir, o agir e o porvir.

Por esta prática insistente e investigativa (laboratórios) é possível exercitar e aprofundar a compreensão, em corpo, que pode fundamentar e dar materialidade aos princípios propostos que, em treinamentos de energia, atuam como transformadores da qualidade do trabalho corporal nos quais a embriogênese se vincula à cosmogênese e microcosmo ao macrocosmo a serviço do desenvolvimento do corpo-pensamento, da percepção, da imaginação, da memória e da consciência, ou seja, nada fazer e que nada deixe de ser feito (JULIIEN, 1998, p. 107).

Chamamos a atenção tanto para o espaço de treinamento quanto para o espaço de criação propostos não como resultado da consciência ${ }^{21}$ e, sim, como um meio e uma dinâmica para se chegar a ela, porque a criatividade é antes descobrir o que não se conhece (GROTOWSKI, 2007, p. 227). É preciso, por conseguinte, aprender como exercitar-se de maneira sincera, ${ }^{22}$ atitude que implica no como se concentrar, para, então, descobrir como doar-se. Aquilo que se faz é preciso fazê-lo até o fim. É preciso se dar inteiramente, superando as fronteiras da cotidianidade, de modo tangível, de verdade. Então existe a concentração. Quando existe a doação, existe concentração (GROTOWSKI, 2007, p. 210).

21 Para uma consciência que se exprime, o primeiro bem é uma imagem, e os grandes valores dessa imagem estão em sua própria expressão. Uma consciência que se exprime! Haverá outras? (BACHELARD, 1971 apud FERREIRA, 2008, p. 46).

220 problema da sinceridade - da sinceridade consigo mesmo - existe aonde há a revelação, não aonde se treina (GROTOWSKI, 2007, p. 201).
Queremos com esta aproximação, experimental, abrir espaços para investigações sobre a motilidade da presença cênica e da imaginação, a partir de certa presença do ator sobre si mesmo, a qual tem materialidade orgânica, celular, energética e funcional, em um outro eixo.

A transformação psicossomática da ansiedade e a desaceleração mental podem potencializar e ampliar a autopercepção das sensações em corpo-ator, que são compreensões em desenvolvimento técnico simples e indispensáveis, as quais podem se complexificar na justaposição daquilo que se treina, do como se treina e, ainda, o quanto se treina. Ou seja, ao apresentar a polaridade não-agir (como sensibilidade, como energia, como imaginação e, ainda, como o silêncio que gera o novo e cria o elo com o invisível) estamos reafirmando a importância do agir, da transpiração, da insistência, da paciência e de um método em treinamento como condição para a exploração de camadas mais profundas e maissutisdaimaginaçãocomomaterialidade poética em corpo-ator, em outras palavras, a forma serve para a expressão da energia.

O treinamento vivo, deste modo, torna-se indispensável à percepção e à materialização daquilo que pode ser o 'acaso', já que é da interação dinâmica entre o método e o desconhecido que existe a lacuna, ou seja, as possibilidades de interações, atualizações e criações.

Tais treinamentos em seus processos evolutivos podem, pela insistência sistematizada e investigativa, levar à ampliação da percepção e da consciência - a do ator sobre si mesmo e sobre seu ofício. Ou seja, propomos a construção de bases técnicas e criativas que investiguem as origens da ação (a cada vez) e suas compreensões mais sutis em camadas mais internas do corpo (motilidade), as quais, quando em processos poéticos, só se fazem em conjunto com a ação da imaginação, pela qual é possível atingir a singularidade e a subjetividade como materialidade criativa e autógena em corpo-ator, ou seja, uma possibilidade de correspondência com a verticalidade do instante poético em Bachelard. 
Segundo Grotowski (2007), sob a luz de suas investigações intensas em laboratório, o resultado (efeito) está na passagem do pesado para o sutil. Reconhecemos como 'passagem' as transformações qualitativas (verticalidade), os voos poéticos (os pequenos e os grandes) que acontecem no trabalho do ator, os quais estão vinculados ao trabalho do ator sobre si mesmo, e que são acontecimentos, percepções e transformações profundas da materialidade corporal (psicofísica, energética), isto é, em corpo-ator.

Deste modo, o treinamento para o ator implica no exercício constante da sua imaginação como materialidade corporal viva, que é apresentada como elemento vital no método das ações-físicas, elemento que Stanislávski faz questão de diferenciar da fantasia, devido ao seu caráter psicossomático; ou seja, a imaginação viva no ator implica no engajamento celular, logo ela acontece enraizada no soma, como matéria poética do ser.

Trata-se, portanto, de reorganizações psicossomáticas que podem materializar outros padrões para agir (estados) transformação indispensável a qualquer criação e composição cênica. Deste modo, a alteração do padrão da respiração em corpo-ator significa a transformação do tempo-ritmo ${ }^{23}$ em ação, que se faz pela

23 Tempo-ritmo é o elemento do método stanislavskiano das ações-físicas que organiza a materialidade da ação como tempo-ritmo em corpo-ator. "É antológica a experiência que realizou junto aos atores-cantores com uma dezena de metrônomos, [...],produzindo os mais variados ritmos, experimentando diferentes atmosferas, estados de ânimo e situações.[...].Mas foi em seus últimos anos de vida, trabalhando no Estúdio de Ópera e Artes Dramática com jovens cantores e atores, que conseguiu realmente verificar o estreito vínculo do método das ações-físicas com o temporitmo interno e externo (DAGOSTINI, 2007, p. 90). As pesquisas de K. Stanislávski nesse campo se dirigiram, sobretudo, ao estabelecimento de uma psicotécnica que elevasse a arte do ator a uma precisão absoluta da ação psicofísica e da linguagem, correspondendo a uma partitura musical. Com o domínio deste recurso, que se encontra estreitamente vinculado à respiração e à atenção, todos os outros elementos da arte do ator, [...] seriam desencadeados, pois o temporitmo constitui-se num meio direto e imediato para estimular as forças motrizes da vida psíquica: a mente, a vontade e o sentimento.(DAGOSTINI,2007, p. 92). transformação dos estados, os quais, por sua vez, estão vinculados à imagem em imaginação. $\mathrm{O}$ tempo-ritmo está presente na imaginação, no pensamento, na comunicação, nos sentimentos. (DAGOSTINI,2007, p.92)

Assim, ao direcionar o não-agir de processos criativos cênicos ele fundamenta a base de experiência na vivência (investigativa) dos treinamentos pelos quais o ator pode, a partir da auto-observação de si, conhecer seus padrões, pontos de tensão e pontos de relaxamentoe, a partir destas investigações, trabalhar para aprender como transformálos, e, por estes processos internos (de elaboração) aprender como gerar os espaços solitários e férteis em si mesmos (lacunas, conexões) para as atualizações, criações e recriações. É que a força do ritmo atua de forma direta e imediata sobre o estado físico e psíquico que influencia o domínio dos músculos e se expressa externamente em todo aparato físico. (DAGOSTINI, 2007, p. 92)

Objetivamente, o que queremos dizer é que o ator, ao focar sua atenção, excessivamente, na execução da forma (seja em treinamento seja no personagem) ele fecha certos espaços, os quais, quando abertos, podem gerar o estado de disponibilidade (que sabe como retornar às origens da ação para revivescer, nãoagir para agir) de questionamentos, de investigações e de atualizações. Ou seja, sem a curiosidade e a atenção àquilo que é vivo no momento, a percepção e atenção podem se enrijecer (fixar) por estar predominantemente direcionadas ao aspecto mais aparente (consciente), e, assim, o trabalho perde a dinâmica da renovação que refresca, ele não integra o que emerge do inconsciente e do momento.

$\mathrm{Na}$ atitude-condição incompleta, portanto, - a do agir excessivo, imposto, como polaridade desconexa do não-agir sob a luz taoísta, reside a impossibilidade da conexão, da evolução e da eficácia, porque esta relação conduziria à cisão entre 
os polos, logo, à imobilidade ${ }^{24}$ da dinâmica. Enquanto que o agir provocado, alimentado e interado no não-agir preservaria a dinâmica da presença, na qual somos ativos e totalmente passivos ao mesmo tempo. Em que a presença do outro se manifesta por si só, sem que se procure. Quando é eliminada toda a diferença entre corpo e alma. Naquele momento podemos dizer que não estamos divididos (GROTOWSKI, 2007, p. 211).

A ideia da repetição, por conseguinte, como um impulso organizador para agir (aquele que parte apenas dos elementos conhecidos, forma) não levaria à eficácia, como organicidade, por sugerir um excesso de saber e de controle, ou seja, certa rigidez. No lugar da palavra 'controle', deste modo, propomos a expressão 'domínio técnico', que interado de certa disponibilidade interna (imaginação, curiosidade, concentração, atenção e escuta sensível) se funde ao inédito do momento até em suas sutilezas, e, juntos, podem possibilitar um saber retornar às origens da ação, em estado pleno de curiosidade e de atenção, ou seja, um caminho que une a precisão e a espontaneidade.

Por este caminho, portanto, é que se faz a dinâmica entre aquilo que é codificado (ação ou forma ou partitura) e ao mesmo tempo desconhecido (não-ação, não-forma, nãosaber-inconsciente). Deste modo, propomos a motilidade da presença pela percepção que absorve a novidade que emerge do momento presente e, por ela, motilidade, o corpo-ator pode se refazer, se reconstruir e se autocriar. Podemos ilustrar esta atitude em movimento pelo imaginário taoísta,

24 É preciso esclarecer que imobilidade, neste contexto, não tem relação com a "imobilidade dinâmica" utilizada pela antropologia teatral (BARBA e SAVARESE, 1995) para definir estado em que o corpo aparentemente imóvel, internamente continua em ação, neste caso a 'imobilidade' é apenas externa e não imobilidade de ação. Para Stanislávski (apud DAGOSTINI, 2007) 'imobilidade' foi utilizada para apresentar a potencialização interna da dramaticidade, ou seja, para os dois a terminologia aponta o mesmo sentido dramático. Imobilidade, aqui, resgata a premissa de imanência e, por isso, a terminologia está associada com as ações desconexas daquilo que é imanente e, por isso, sem possibilidade de movimento, logo, sem possibilidade de evoluir. como o corpo do dragão-serpente, ela reage em todos os sentidos (serpente do monte Chang proposta como modelo de estratégia): 'Quando a atacam na cabeça, é a cauda que se ergue; quando atacam na cauda, é a cabeça que se ergue, quando atacam no centro, as duas extremidades se erguem ao mesmo tempo'. Como esse tratado de diplomacia o resume, a reação 'não tem lugar próprio', ela pode produzir em qualquer ponto e em qualquer momento. Em uma palavra, não é localizável; sendo assim, está de acordo com a ubiquidade operatória da transformação (JULLIEN, 1998, p. 123).

Seguindo adiante com as imagens que ilustram o princípio da eficácia e da mutabilidade, Jullien (1988) apresenta a recepção (não-agir) que gera a mobilidade necessária ao espírito, ${ }^{25}$ utilizando mais uma vez o imaginário mitológico e animalizante chinês para revelar a dinâmica eficaz do 'agir'(sob o duplo pressuposto) como o dragão:

A imagem da serpente ou, melhor ainda, do dragão exprime bem essa mobilidade do espírito que permite evoluir à vontade, sem jamais ser estorvado nem sofrer (evolução opondo-se a ação): o corpo maleável do dragão não tem forma fixa, ele ondula e se curva em todos os sentidos, contrai-se para distender, concerta-se para progredir; ele esposa tão bem as nuvens que, sempre levado por elas avança sem fazer esforço. Por isso, quase não se distingue delas. Do mesmo modo, a intencionalidade estratégica não tem intenção definida, ela não se obstina em nenhum plano para melhor seguir todos os contornos da situação e pode aproveitá-los: se o estrategista não age, é

25 Ao espírito resta a tarefa de fazer sistemavs, de agenciar experiências diversas para tentar compreender o universo. Ao espírito convém a paciência de instruir-se ao longo do passado do saber. 0 passado da alma está tão longe! A alma não vive ao fio do tempo. Ela encontra seu repouso nos universos imaginados pelo devaneio. Acreditamos, pois, poder mostrar que as imagens cósmicas pertencem à alma, à alma solitária, à alma princípio de toda solidão. As ideias se aprimoram e se multiplicam no comércio dos espíritos. As imagens, em seu resplendor, realizam uma comunhão muito simples das almas. Dois vocabulários deveriam ser organizados para estudar, um o saber, outro a poesia (...) Seria vão constituir dicionários para traduzir de uma língua para outra (BACHELARD, 2006, p. 15). 
porque ele não fragmenta nem depende sua energia numa ação determinada, mas como o corpo infinitamente solto do dragão, vale-se da renovação da situação para - evoluindo sempre - não cessar de avançar (JULLIEN, 1998, p.121).

Para os chineses, todavia, as imagens da serpente e do dragão são mais que metáforas, elas são símbolos vivos enraizados na filosofia e no imaginário mitológico e corporal, e, por meio deles um caminho à evolução (saber integrarse àquilo que já existe e agir junto). Para isso, é preciso saber como melhor utilizar a energia e o sentido imanentes e, com uma atitude 'quase que invisível', saber moverse de forma integrada, o que nos leva a insistir que o não-agir não é um abandono do agir, ele é vivo e possui critérios.

Compreendemos o agir 'quase que invisível', na condição corpo-ator, como a apropriação técnica (adaptação stanislavskiana) e a superação técnica que, neste nível de autodomínio cênico, causa o efeito da naturalidade no agir, ou seja, a segunda natureza stanislavskiana.

Sob a realidade da imaginação em corpo-ator não há cisão entre sujeito e objeto (nuvens e dragão), um alimenta-se nas provocações do outro e, pela dinâmica mutante, é possível materializar a unidade como autocriação em transformação constante.

Desta perspectiva, pelo duplo pressuposto taoísta, também não há cisão entre a vivência em corpo-ator e a reflexão que se faz, ambas se fundem como experiência. Ou seja, a respiração é que relaxa a musculatura para que esta se alongue um pouco mais pelo fluir da energia, e não a força; pulsa no mesmo corpo que respira o texto para perceber um sentido a mais no pensamento que se faz. Na interação dinâmica entre a imaginação e a atenção, encontramos a ação e a contemplação (não-ação) e assim identificamos, mais uma vez, em texto, o princípio não agir para agir.

Nessa contemplação em profundidade, o sujeito toma também consciência de sua intimidade. Essa contemplação não é, pois, uma Einfühlung imediata, uma fusão desenfreada. É antes uma perspectiva de aprofundamento para o mundo e para nós mesmos. Permite-nos ficar distantes diante do mundo. Diante da água profunda, escolhes tua visão; podes ver a vontade o fundo imóvel ou a corrente, a margem ou o infinito; tens o direito ambíguo de ver e de não ver (...) (BACHELARD, 1947 apud FERREIRA, 2008, p. 47).

Sobre esta perspectiva-experiência, segundo Jullien (1998): Esposar o curso espontâneo das coisas, responder-lhe "como fêmea", tal como recomenda o LAOZI (...), permite conceber a conduta não mais em termos de ação e sim de reação (...); e esse insinuar-se basta para mudar globalmente as perspectivas (JULLIEN, 1998, p.121).

Esta brevíssima apresentação da polaridade não-agir (integrada ao agir) tem com objetivo apontar o sentido do qual emergiu e, por aquilo que foi 'despertado' e 'atiçado', abrir a possibilidades para investigações em laboratório sobre o princípio da unidade dinâmica que também é o princípio da vida.

Algumas relações, do não-agir para agir em corpo, propostas em práticas corporais chinesas, podem ser identificadas pelo como se propõe o conceito de mutação em movimento, como, por exemplo, no caminhar da forma tai chi chuan pelo qual para se ir a um lado toma-se impulso no outro. Este alimento do agir no lado oposto do corpo, sob a visão da linearidade, pode ser visto como um desvio, o da direção desejada. Porém, sob a lógica chinesa e taoísta, ir ao lado oposto antes de ir à frente não é um desvio, é, sim, a formação, a potencialização e o espaço para a atualização do movimento seguinte, ou seja, é uma estratégia, e, ao mesmo tempo, é um tempo-espaço que possibilita a visão (percepção do dragão).

Assim, neste 'como' caminhar, antes de se dar um passo a frente, há um passo (desvio) para o lado. A sequência é a 
seguinte: para o lado, para frente, para trás, para o outro lado, para frente e para trás, sucessivamente.

Barba(1995), aofalar sobreesteelemento técnico, a dança das oposições, afirma que se quisermos, de fato, compreender a dialética no nível material do teatro é indispensável estudar o princípio das oposições nos atores orientais, que é a base sobre a qual eles, atores orientais, constroem e desenvolvem todas as suas ações. O ator chinês sempre começa uma ação em seu oposto (...) se deseja ir para a esquerda começa indo para a direita, se quer agachar primeiro se levanta na ponta dos pés (BARBA; SAVARESE, 1995, p.176). Deste modo, a centelha da forma está na receptividade da base no lado oposto do corpo; há sempre esta nãoação que é o espaço-momento que esposa o tempo, gera e atualiza a ação, ou seja, o não-agir também tem sua materialidade mutante. Este acontecimento vivo se faz tanto nas relações dos espaços interno e externo em corpo-ator, quanto nas relações dinâmicas entre o ator e o espaço físico. Deste modo, o engajamento global do corpo para agir inclui o espírito e a alma do próprio agir. Portanto, forma e matéria neste processo de mutabilidade compõem uma unidade mutante.

Como vivência, em corpo-ator, a forma (estrutura consciente) não existe sem a nãoforma (fluência de energia, liberdade interior, variáveis do momento,...), e é assim que vinculamos o comprometimento espiritual à expressividade como materialidade artística, e, pela provocação de uma à outra, é possível agir e levar a dinâmica da imaginação adiante. O essencial é que uma imagem seja acertada. Pode-se esperar, então, que ela tome o caminho da alma, que não se embarace nas objeções do espírito crítico, que não seja detida pela pesada mecânica dos recalques. (...) $\mathrm{O}$ devaneio nos põe em estado de alma nascente (BACHELARD, 2006, p.15).

Cabe insistir, por conseguinte, que o foco da qualidade proposta (como efeito da unidade) não está nem no eixo do agir e nem no eixo do não-agir, mas, sim, naquilo que resulta da interação entre ambos no momento, ou seja, nos vínculos pelos quais as relações podem ser estabelecidas e desenvolvidas; nelas, nas relações vivas (dinâmica) é que se encontram as possibilidades reais de transformação, ou seja, a sensibilidade, o senso da realidade imaginada e o autodomínio técnico atuam como unidade, e, assim, a profundidade do aprimoramento de um elemento se dá em justaposição com os outros.

Sobre estes efeitos não-agir para agir, Grotowski apud Barba e Savarese fala da sua existência na vida normal em técnicas cotidianas, mas que, em corpoator, em situação de representação há uma amplificação extrema, que resulta algo que possui outra qualidade (GROTOWSKI apud BARBA; SAVARESE, 1995, p. 236).

Aprender corretamente a forma dos exercícios (uma forma de caminhar ou de se mover), entretanto, não é o objetivo em si, mas, sim, a possibilidade de transformação corporal, na qualidade com que ela é executada em corpo-ator; ou seja, quando não-agir e agir atuarem, um sob a provocação e influencia do outro, como um processo contínuo sob qual só é possível identificar apenas a continuidade.

Assim, ao utilizarmos o princípio nãoagir para agir em investigações corporais, propomos um modo para encontrar um ponto de conexão, uma abordagem que inclui a receptividade como alimento e, principalmente, um espaço silencioso e solitário de comunicação e criação em corpo-ator. O devaneio cósmico (...) é um fenômeno da solidão, (...) que tem sua raiz na alma do sonhador. Não necessita de um deserto para estabelecer-se e crescer. Basta um pretexto - e não uma causa para que nos ponhamos em 'situação de solidão', em situação de solidão sonhadora (BACHELARD, 2006, p.14).

Enlaçamo-nos na eficácia do pretexto para que na condição corpo-ator 'nos ponhamos em situação de solidão' (bachelardianos), como as compreensões psicotécnicas (fenomenotécnicas) e individuais indispensáveis aos 
treinamentos e aos processos criativos. Assim, evidenciamos ainda mais o eixo que move a materialidade cênica corpoator, no trabalho do ator sobre si mesmo; ou seja, a disponibilidade e a curiosidade que geram certa atitude em face ao método, a do eterno retorno às origens para saber como, a cada vez, se colocar em situação.

Sobre a potência não-forma Grotowski utiliza as expressões subleis, antiimpulso ou anti-movimento. Deste modo, Grotowski afirma sua materialidade dinâmica (a não-forma por ele: antiimpulso ou anti-movimento) isso é muito concreto, ele existe. Pode ocorrer em níveis diferentes, como uma espécie de silêncio antes do movimento, um silêncio preenchido com o potencial (GROTOWSKI apudBARBA;SAVARESE 1995, p. 236).

As investigações brevemente organizadas (apontadas) neste texto têm o propósito de flexibilizar e abrir lacunas à metodologia de abordagem do treinamento, da docência e dos processos criativos e, assim, aproximar o ator um pouco mais de seus objetivos criativos, por meio das experimentações em corpoator a partir das conexões internas de energia (silêncio, solidão, concentração) pelas quais ele poderá conectar-se em 'si mesmo' e a partir deste espaço aberto a comunicação possibilitar diálogos internos (imaginação enraizada no soma) como que devaneios em expressividade corporal ele possa trabalhar sobre si mesmo e se autocriar poeticamente:

o devaneio poético nos dá o mundo dos mundos. O devaneio poético é um devaneio cósmico. É uma abertura para um mundo belo, para mundos belos. Dá ao eu um não-eu que é o bem do eu: o não-eu meu. É esse não-eu meu que encanta o eu do sonhador e que os poetas sabem fazer-nos partilhar. Para o meu eu sonhador, é esse não-eu meu que me permite viver minha confiança de estar no mundo. Em face de um mundo real, pode-se descobrir em si mesmo o ser da inquietação. Somos então jogados no mundo, entregues à imunidade do mundo, à negatividade do mundo, $\mathrm{o}$ mundo é então o nada humano (...) (BACHELARD, 2006, p.13).

O objetivo das lacunas é, ainda, o de investigar a atitude receptiva, estado, como um recurso a mais nos estudos da concentração, da percepção, da atenção e da ação convergentes sob a imaginação, em corpo-ator.

Deste modo, as experimentações insistentes com atenção e calma, em laboratório, podem investigar, um pouco mais, a compreensão psicofísica daquilo que, ocidental e coletivamente, denominamos como método e procedimentos técnicos; organizadores que reconhecemos individualmente como psicotécnica, os quais, sob o princípio da mutabilidade, possivelmente poderiam ser identificados como um caminho.

A palavra Caminho foi utilizada como tradução de Tao, mas também é sabido que o Tao absoluto não pode ser dito e que, quando dito, não é mais o Tao Verdadeiro. ${ }^{26}$. Este aforismo, para os chineses, não é um paradoxo, é, sim, a abertura que possibilita a interação e a continuidade; ou seja, é o espaço disponível àquilo que não pode ser dito e nem antecipado, mas, sim, experienciado em seu tempo.

26 Watts (1999) nos fala sobre as diferentes terminologias usadas para traduzir TAO e das dificuldades existentes (dificuldades de quê/para quê?). Para exemplificar, ele diz: Assim o TAO TE CHING se inicia com as palavras enigmáticas, em geral traduzidas como "o TAO que pode ser dito não é o TAO eterno". Esta tradução oculta o fato de que o ideograma traduzido como "QUE PODE SER DITO" é igualmente o TAO, porque essa palavra também significa 'falar' ou 'dizer', conquanto possivelmente não tivesse essa utilização no século 3. Literalmente, diz a passagem: 'Tao pode ser Tao não eterno ou [regular] Tao (WATTS, 1999, p.69). 0 autor segue apresentando tantas outras possibilidades de traduções e por consequência de interpretações. Wilhelm (1995) também diz: A mutação não é desprovida de sentido - se o fosse não seria possível formular qualquer conhecimento a seu respeito -, mas está sujeita à lei universal do TAO (WILHELM, 1995, in introdução IChing). 


\section{Referências bibliográficas}

BACHELARD, G.. L'eau et les rêves. Essai sur l'imagination de la matèrie. Paris: José Corti, 1947.

La terre et lês rêveries du repos. Essai sur lês images de l'intimité. Paris: José Corti, 1971. A Poética do Espaço. São Paulo: Martins Fontes, 1993.

A Poética do Devaneio. São Paulo: Martins Fontes, 2006.

. O Ar e os Sonhos: ensaio sobre a imaginação do Movimento. São Paulo: Martins Fontes, 2001.

BARBA, E.; SAVARESE, N. A Arte Secreta do Ator: Dicionário de Antropologia Teatral. Campinas: Ed. Unicamp, 1995.

DAGOSTINI, N. O método de análise ativa de K. Stanislávski como base para a leitura do texto e da criação do espetáculo pelo diretor e ator. 2007, 259 pgs Tese de Doutorado. Faculdade de Filosofia, Letras e Ciências Humanas/USP: São Paulo, 2007.

FERREIRA, E. E. A. Dicionário de Imagens, símbolos, mitos, termos e conceitos Bachelardianos. - Londrina: EDUEL, 2008.

JULLIEN, F. Tratado da Eficácia. São Paulo: Ed. 34, 1998.

Do "tempo". Elementos para uma filosofia do viver. São Paulo: Discurso Editorial, 2004.

JUNG, C.G. O Espírito na Arte e na Ciência. $3^{\mathrm{a}}$ ed. Tradução Maria de M. Barros. Petrópolis: Vozes, 1991.

KELEMAN, S. Anatomia Emocional. São Paulo: Summus, 1992.

LOWEN, A. Exercícios de bioenergética: o caminho para uma saúde vibrante. São Paulo:Ágora, 1985.

Alegria: a entrega ao corpo e à vida. $3^{\text {a }}$ ed. São Paulo: Summus, 1997.

RIBAS, M. M. A imaginação do ator, um vôo indizivel. 2009, 278 pgs .Tese de Doutorado. Instituto de Artes/UNICAMP: Campinas, 2009.

RUFFINI, F. “Sistema” de Stanislávski apud BARBA e SAVARESE, 1995, p.150.
A mente Dilatada apud BARBA e SAVARESE, 1995, p.64.

STANISLÁVSKI, K.Sobránie sotshineni v 8 tomak, 1954-1961. Rabota aktiora nad

soboi. Rabota nad soboi v tvórtcheskom protsésse-perijivânia. Tomo 2, Moscou: Iskusstvo,1954

VINOGRADSKAIA I. N. (org.) Stanislávski Repetíruet. Moscou: MKHT, 2000.

WATTS, A. Tao - o curso do rio. São Paulo: Pensamento, 1997.

WILHELM, R. (Trad.). I Ching, O Livro das Mutações. São Paulo: Pensamento, 1995. 